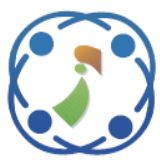

\title{
Intelligent SMES based on Flower Pollination Algorithm on Wind Power System for Dynamic Stability Enhancement
}

\author{
Herlambang Setiadi ${ }^{1 *}$ \\ Dimas Anton Asfani \\ Tigor Hamonangan Nasution ${ }^{3}$ \\ Muhammad Abdillah ${ }^{4} \quad$ Awan Uji Krismanto $^{5}$ \\ ${ }^{I}$ Department of Advanced Technology, Faculty of Advanced Technology and Multidiscipline, \\ Universitas Airlangga, Surabaya, Indonesia \\ ${ }^{2}$ Department of Electrical Engineering, Faculty of Intelligent Electrical and Informatics Technology, \\ Institut Teknologi Sepuluh Nopember, Surabaya, Indonesia \\ ${ }^{3}$ Department of Electrical Engineering, Engineering Faculty, Universitas Sumatra Utara, Medan, Indonesia \\ ${ }^{4}$ Department of Electrical Engineering, Faculty of Industrial Technology, \\ Universitas Pertamina, Jakarta, Indonesia \\ ${ }^{5}$ Department of Electrical Engineering, Engineering Faculty, \\ Institut Teknologi Nasional Malang, Malang, Indonesia \\ * Corresponding author's Email: h.setiadi@stmm.unair.ac.id
}

\begin{abstract}
Integration of large-scale wind power plant (WPP) in transmission level is becoming reality due to reduce dependency on fossil fuels resources. Although, WPP could provide clean and sustainable energy, they also contribute in instability of power system especially on small signal stability due to uncertainty of the power output. Hence, utilizing additional devices such as energy storage can be considered to handle the uncertainty power output of WPP. This paper proposes an application of superconducting magnetic energy storage (SMES) as an additional device to provide a better damping of frequency oscillation and enhance the small signal stability performance of a power system affected by integrating of large-scale WPP. To get better performance, the parameters of SMES are automatically adjusted by using flower pollination algorithm (FPA). Eigenvalue, damping performance and time domain simulation are investigated to analyze the robustness and successfulness of the proposed method. From the simulation result, it is found that the proposed method (adding SMES on WPP using FPA) can enhance the small signal stability performance of the system. It is indicated by the TKE value of the proposed method is the smallest compared to the other scenarios (0.000017).
\end{abstract}

Keywords: Clean energy technology, FPA, Oscillatory stability, Renewable energy, SMES.

\section{Introduction}

Society all over the world in recent years has face a big problem such as global warming. Global warming emerges due to greenhouse gas effect from the application of fossil fuels in many sectors [1]. To prevent the further damage, reducing the application of fossil fuels in power sectors is crucial. Hence, integrating power plant based on renewable energy sources (RESs) is inevitable to reducing greenhouse gas effect from the power sectors [2]. Among numerous types of RESs wind power system are assumed to have the most promising prospect in power sector. However, wind power plant (WPP) has a handicap in terms of uncertainty power output and inertia-less characteristic. This handicap could contribute to the instability of power system. One of the stabilities that can have impact in integration of WPP is small signal stability [3].

Small signal stability is the ability of the system to maintain its stable condition after addressed by small disturbance. Oscillatory condition related to 
local and inter-area electromechanical modes among synchronous generators have dominated this stability. Conventionally, this stability primarily dealt by adding damper windings in the system and installing PSS in exciter. PSS has shown a good performance over the decade to enhance the small signal stability problem of the power system. However, with largescale integration of uncertain and inertia-less characteristic of WPP, PSS alone is out of date for handling this problem. Hence, adding additional devices such as energy storage in large-scale WPP can be considered to overcome the uncertainty problems of WPP.

In power system sectors, there are a numerous type of energy storage that has been used to handle some problems. Energy storage such as capacitor energy storage [4], redox flow batteries [5], battery energy storage systems [6]. As reported in [4], capacitor energy storage can be used to regulate frequency in multisource and multiarea power system. Research effort in [5], shows that frequency stability of power system can be enhanced by adding redox flow batteries in the system. Battery energy storage is also shows promising results in enhancing stability of power system considering uncertainty of the renewable energy as reported in [6]. Moreover, superconducting magnetic energy storage (SMES) [7] have been used to solve voltage, frequency as well as small signal stability problems. Among them, SMES is becoming more favorable due to the fast response and large capacity. The biggest challenge in here is how to design SMES parameter in large-scale WPP and make the system secure and reliable. Generally, designing SMES is used complex mathematical approach. This process requires huge efforts and tend to have huge errors. Hence, designing SMES based on metaheuristic algorithm can be considered to minimize the complexity and the errors.

Metaheuristic algorithm can be categorized into three groups: Physical based inspiration, social based inspiration, and biological based inspiration. Among the type of metaheuristic algorithm, biological based inspiration become very attractive in recent years. Genetic algorithm (GA) [8], particle swarm optimization (PSO) [9], artificial immune system (AIS) [10] and differential evolution algorithm (DEA) [11] fall under biologically inspired algorithm. Many papers have been published in the field of parameter tuning using metaheuristic algorithm. A method based on GA to tune PSS parameter is presented in [12]. The application of particle swarm optimization for sizing battery energy storage in micro grid system is reported in [13]. DEA is also can be used as intelligence method to design wide area power oscillation damping on a renewable rich power system [14]. Recently, firefly algorithm method has been applied to solve the optimization problem, and this algorithm shows a good performance [15]. Cuckoo search algorithm (CSA) is metaheuristic method inspired by the behavior or habits of daily living cuckoo bird in the breed, this method was developed by Xin-She Yang in 2009 [16]. Recently, the application of flower pollination algorithm is becoming favorable for solving power system problem. As reported in [17], FPA shows an optimal solution for PID controller as the multi-source power system controller

This paper proposed the enhancement of small signal stability performance by employing SMES in power system network affected by large-scale WPP penetration. To get better performance, the parameters of SMES are optimized using FA. The rest of this paper is organized as follows: section II briefly explains the modeling of WPP, SMES and power system. The basic theory of FA and designing SMES based on FA is introduced in section III. Section IV shows the result and discussion of eigenvalue, damping value and time domain simulation. Section V highlights the conclusions, contribution and future direction of this research.

\section{Modelling}

\subsection{Wind power plant}

For dynamic stability analysis, one of the most important things is how to capture and model the dynamic representation of the system. In this paper, wind power plant is modeled as aggregated model of permanent magnet synchronous generator-based wind power plant. In this paper the wind power plant is consist of permanent magnet synchronous generator (PMSG), converter, and the associated controller. The dynamic mode of WPP based on PMSG is depicted in Fig. 1 [18]. The aerodynamics of the rotor are presented using (1) [19]-[21]. While, the mathematical model of PMSG is given by (1), (2) and (3) [19]-[21].

$$
\frac{d_{i d}}{d_{t}}=\frac{1}{L_{d s}+L_{i s}}\left(-R_{s} i_{d}+\omega_{e}\left(L_{q s}+L_{i s}\right) i_{q}+u_{d}\right)
$$

$$
\frac{d_{i q}}{d_{t}}=\frac{1}{L_{q s}+L_{i s}}\left(-R_{s} i_{q}+\omega_{e}\left[\left(L_{d s}+L_{i s}\right) i_{q}+\psi_{f}\right]+\right.
$$$$
\left.u_{d}\right)
$$

$\omega_{e}=p \omega_{g}$

To complete the representation of the WPP based PMSG, electromechanical torque representation is 


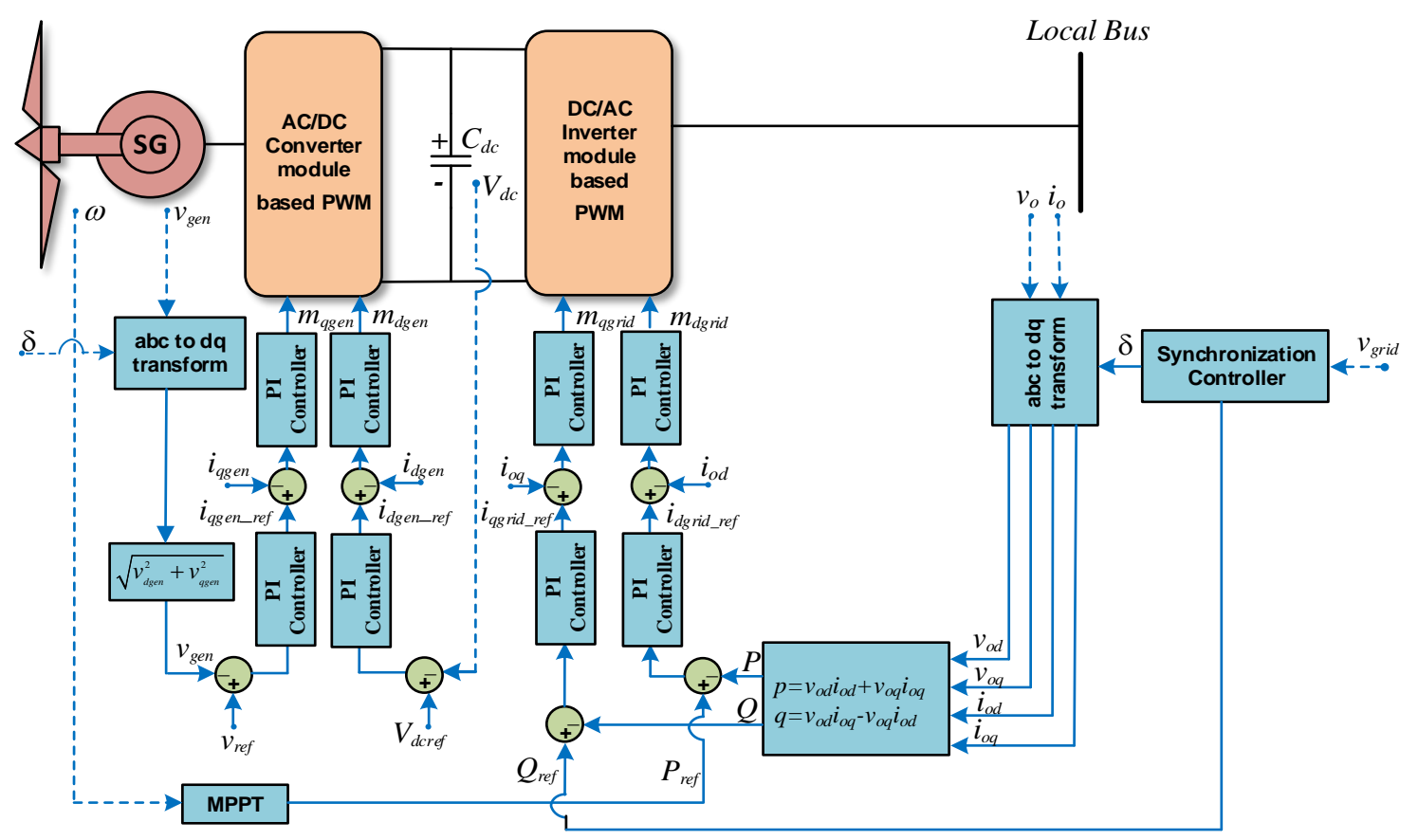

Figure. 1 Dynamic model of WPP based PMSG

inevitable. Electromechanical torque equation as dictated in (4) is considered to complete the PMSG model. Moreover, detailed model of WECS based on PMSG can be seen on [19]-[21].

$$
\tau_{e}=1.5 p\left(\left(L_{d s}+L_{i s}\right) i_{d} i_{q}+i_{q} \psi_{f}\right)
$$

\subsection{SMES dynamic representation}

Superconducting magnetic energy storage (SMES) consists of three important parts namely, superconductor coils, power conversion system, and cryrogenic systems. The superconductor coils are utilized to store electrical energy in large amount, while the cryrogenic system is used to maintain the temperature of the superconductor coils. Power conversion system (PCS) is used as interface between the superconducting coils with grid or systems [7].

For small signal stability study, capturing the dynamic behavior of SMES is crucials. The dynamic model of SMES comprises of superconductor dynamic, converter dynamic and its associated controller. The mathematical representation of SMES can be expressed using (5), (6), and (7) [22].

$$
\begin{gathered}
\Delta E_{d}=\frac{1}{1+s T_{d c}}\left[k_{0} \Delta \omega-k_{i d} \Delta I_{d}\right] \\
\Delta I_{d}=\frac{1}{L_{s}} \Delta E_{d} \\
\Delta P_{S M E S}(t)=\Delta I_{d 0} \Delta E_{d}+\Delta I_{d} \Delta E_{d}
\end{gathered}
$$

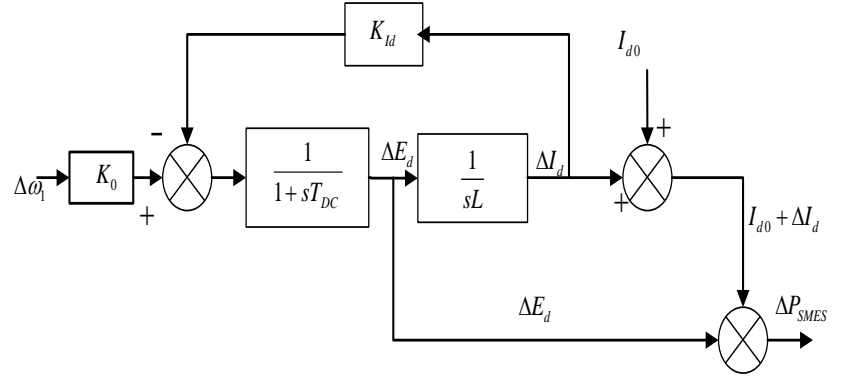

Figure. 2 Block diagram of SMES

Where $T_{d c}$ is the converter time delay, $I_{d}$ is the current flowing through the inductor, $E_{d}$ is DC voltage applied to the inductor, $k_{0}$ is gain constant, $L$ is the inductance coil, $k_{i d}$ is the feedback gain. Block diagram of SMES for small signal stability study is shown in Fig. 2 [22].

\section{Method}

\subsection{Flower pollination algorithm}

Flower pollination algorithm (FPA) is an algorithm created by Dr. Xin She Yang that propelled by the bloom fertilization peculiarities. This algorithm comprises of four significant guidelines [23]. The main guideline is biotic fertilization and cross fertilization that are portrayed as worldwide fertilization system with dust conveying pollinators doing the levy flights. The subsequent principle is the neighborhood fertilization that can portrayed as selffertilization and abiotic process. The third principle is the similitude of two blossoms that is relative to the likelihood of the generation. Besides, proliferation 
likelihood is characterized as the bloom consistency. The last principle is in the general fertilization exercises, the actual closeness and different factors like breeze, that can have a critical factor [23]. In addition, switch likelihood could be utilized to control the nearby and worldwide fertilization.

For straightforwardness reason, it is expected that each plant just has one bloom. Additionally, each bloom could just deliver one dust gamete. Consequently, a blossom as well as a dust gamete can be portrayed as an answer xi. From every one of the assertions above, it tends to be expressed that there are two significant keys in FPA nearby and worldwide fertilizations. At the worldwide fertilization step, dust from blossoms is conveyed by pollinating creatures like creepy crawly. In addition, the dust can go in the significant distance because of the bug that can move in huge regions. This long travel dust can guarantee the propagation and fertilization getting the ideal outcomes. These ideal outcomes can be indicated as $\mathrm{g}_{*}$. By thinking about this cycle, the main guideline including the rose consistency can be introduced in (8) [23].

$$
x_{i}^{t+1}=x_{i}^{t}+L\left(x_{i}^{t}-g_{*}\right)
$$

In (8), $\mathrm{g}_{*}, x, i, L, t$ are described as the current best solution, solution vector, pollen, strength of the pollination and the iteration. Levy flight is considered to represent the movement of the insect. Hence, the levy flight $(L)$ can be described as (9) [23].

$$
L \sim \frac{\lambda \Gamma(\lambda) \sin \left(\frac{\pi \lambda}{2}\right)}{\pi} \frac{1}{s^{1+\lambda}},\left(s>>s_{0}>0\right)
$$

In (9), standard gamma function, and constant value are denoted by $\Gamma(\lambda)$ and $\lambda$. Furthermore, equation (10) described the flower constancy as well as the local pollination phenomena [23].

$$
x_{i}^{t+1}=x_{i}^{t}+\in\left(x_{j}^{t}-x_{k}^{t}\right)
$$

In (10), pollen from the different flowers of the same plant species is denoted by $x_{j}^{t}$ and $x_{k}^{t}$ are described as pollen from the same plant but different flower. By and large, blossom fertilization peculiarities can be happened both in neighborhood and worldwide scales. Blossoms that not really far away area are bound to be pollinated. Subsequently, to mirror this cycle the switch likelihood can be utilized to switch among worldwide and nearby fertilizations. The switch likelihood can be meant by $p$, and the best worth of $p$ in reproduction is 0.8 as announced in [23].

\subsection{Objective function}

In this paper, combination of three different objective function is used. The first objective is described in (11). The purpose of this objective function is to make eigenvalue move to left half plane as far as they can. By using this method, the stability of the system can be enhance [24].

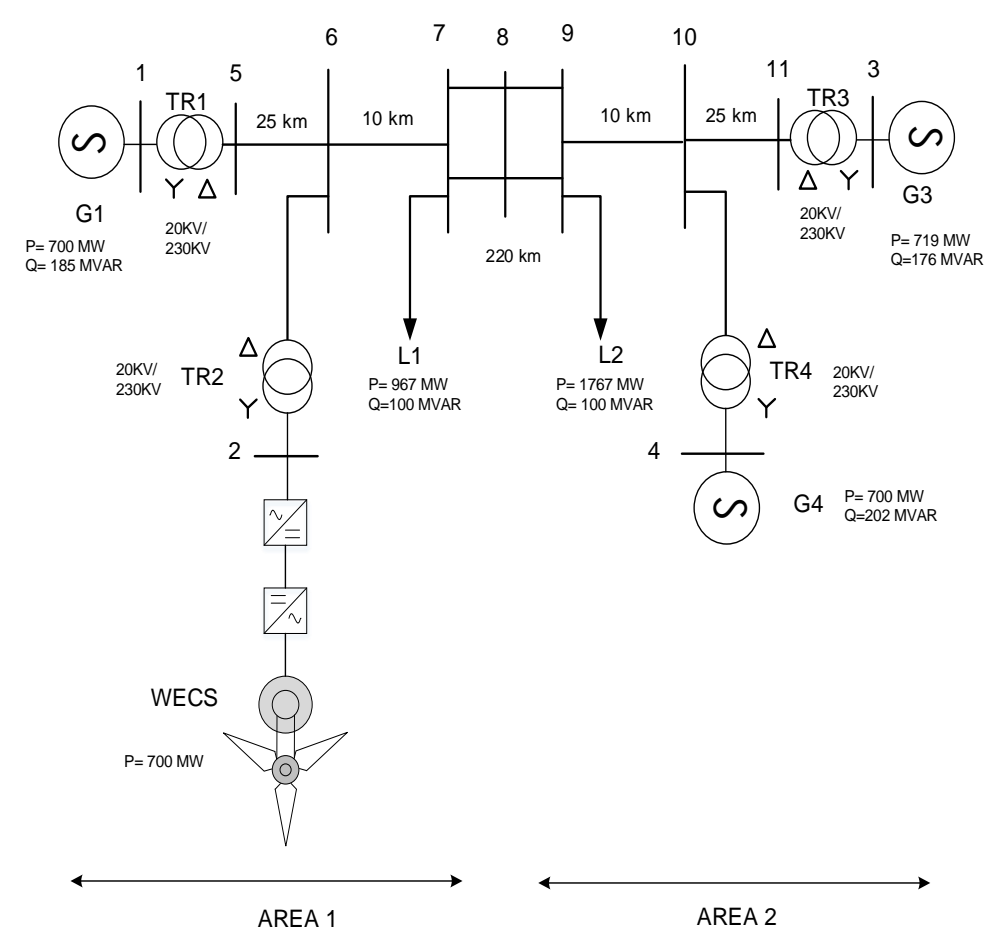

Figure. 3 Test system 


$$
J_{1}=\sum_{\sigma_{0} \geq \sigma_{i}}\left[\sigma_{0}-\sigma_{i}\right]^{2}
$$

In (11), the desired mode location and the real parts of the $i^{\text {th }}$, are denoted by $\sigma_{0}$ and $\sigma_{i} .5 \%$ damping is set as the constraint of the second objective. Eq. (12) is described how to mathematically formulated the second objective [24], [25].

$$
J_{2}=\sum_{\xi_{0} \leq \xi_{i}}\left[\xi_{0}-\xi_{i}\right]^{2}
$$

In (12), the damping value and desired damping value of the $i^{\text {th }}$ eigenvalue are described by $\xi_{i}$ and $\xi_{0}$. The last objective function focused on how to make sure the non-linear time domain simulation is having the minimum error. This objective focused on how to minimize the overshoot and accelerate the settling time. To use the last objective function the mathematical representation in (13) is used. [24].

$$
J_{3}=\sum \int_{0}^{t_{1}} t|\Delta \omega(t, X)| d t
$$

In (13), $\Delta \omega(t, X)$ is the non-linear time domain response of generator rotor speed. $X$ consists of optimized parameters while $t_{1}$ is the time frame of the simulation. Hence, all of the objective function can be combined by using (14) [24], [26].

$$
\text { Objective }=\min \left(a J_{1}+b J_{2}+c J_{3}\right)
$$

Subject to:

$$
\begin{aligned}
& 5 \leq K_{\Delta \omega n} \leq 20 \\
& 5 \leq K_{\Delta \omega n} \leq 20
\end{aligned}
$$

In (14), $a, b$ and $c$ are the normalize factors in the range of 0 to 1 [24].

\subsection{Procedure of designing SMES}

The procedure for designing the controller using flower pollination algorithm can be described by following step.

1. Linearize the nonlinear system.

2. Transform every equation into state space portrayal.

3. Start the FPA by instating the quantity of blossoms, number of iteration and switch likelihood

4. Generate random position of bloom.
5. Evaluate the position of blossom by utilizing the objective function in (14) and track down the underlying best solution.

6. Used levy flight function to calculate $L$ by do the global fertilization using (9) and (10).

7. Choose two arbitrary solution.

8. Do the nearby fertilization.

9. Evaluate the new solution by using the genuine capacity in (14).

10. Update the solution with a new and better one.

11. If the model is fulfilled keep the outcomes, if not back to stage 5 .

12. Print the results.

\section{Results and discussions}

In this research, cases studies were carried on MATLAB/SIMULINK environment. The test system is multi-machine two-area power system. A modification was made in the system by replacing one synchronous generator in area 2 with $700 \mathrm{MW}$ aggregated WPP as shown in Fig. 3. In this study, it is assumed that WPP is operated at the maximum power point condition. The modified system consists of three synchronous generators and one WPP. The WPP is presented by eleventh order model comprises of the wind turbine, drive train, PMSG, converter and the associated controller. The synchronous generator is presented by a ninth order model considering fast exciter and governor. Three different cases studies are carried out to investigate the efficacy of the proposed controller method. The first case study is investigating the modal analysis of investigated system. Non-linear time domain simulation to verify the modal analysis is presented in case study two. In case study three, how much kinetic energy is produced by the system is investigated thoroughly. In addition, Table 1 shows the scenarios used in this paper.

\subsection{Modal analysis}

In this section, modal analysis comparison is conducted. To investigate the modal analysis, eigenvalue, and damping performance are

Table 1. Scenarios

\begin{tabular}{|c|c|}
\hline Scenarios & System \\
\hline $\mathbf{1}$ & No additional controller \\
\hline $\mathbf{2}$ & Replaced with WPP \\
\hline $\mathbf{3}$ & With WPP and SMES \\
\hline $\mathbf{4}$ & Proposed Method \\
\hline
\end{tabular}


Table 2. Eigenvalue and damping comparison

\begin{tabular}{|c|c|c|c|c|c|c|}
\hline \multirow{2}{*}{$\begin{array}{l}\text { Modes } \\
\text { Cases }\end{array}$} & \multicolumn{2}{|c|}{ Local 1} & \multicolumn{2}{|c|}{ Local 2} & \multicolumn{2}{|c|}{ Inter-Area } \\
\hline & Eigen & Damp. & Eigen & Damp. & Eigen & Damp. \\
\hline $\begin{array}{c}\text { Scenari } \\
\text { o } 1\end{array}$ & $\begin{array}{c}- \\
0.325 \pm 6 \\
.758 \mathrm{i}\end{array}$ & 0.048 & $\begin{array}{c}- \\
0.341 \pm 7 \\
018 \mathrm{i}\end{array}$ & 0.049 & $\begin{array}{c}- \\
0.07 \pm 2 \\
609 \mathrm{i}\end{array}$ & 0.026 \\
\hline $\begin{array}{c}\text { Scenari } \\
\text { o } 2\end{array}$ & $\begin{array}{c}- \\
0.278 \pm 6 \\
.539 \mathrm{i}\end{array}$ & 0.043 & $\begin{array}{c}- \\
0.07 \pm 2.6 \\
09 \mathrm{i} \\
\end{array}$ & 0.049 & $\begin{array}{c}- \\
0.05 \pm 2 . \\
911 \mathrm{i}\end{array}$ & 0.017 \\
\hline $\begin{array}{c}\text { Scenari } \\
\text { o } 3\end{array}$ & $\begin{array}{c}- \\
0.3678 \pm \\
6.556 \mathrm{i}\end{array}$ & 0.056 & $\begin{array}{l}- \\
0.339 \pm 7 \\
013 \mathrm{i}\end{array}$ & 0.0483 & $\begin{array}{c}- \\
0.243 \pm 2 \\
.910 \mathrm{i}\end{array}$ & 0.083 \\
\hline $\begin{array}{c}\text { Scenari } \\
\text { o } 4\end{array}$ & $\begin{array}{c}- \\
0.565 \pm 6 \\
.496 \mathrm{i}\end{array}$ & 0.087 & $\begin{array}{c}- \\
0.337 \pm 7 \\
015 \mathrm{i}\end{array}$ & 0.480 & $\begin{array}{c}- \\
0.553 \pm 2 \\
.681 \mathrm{i}\end{array}$ & 0.202 \\
\hline
\end{tabular}

investigated. Table 1 illustrates the eigenvalue and damping ratio of different scenario due to integration of WPP. It is noticeable that by replacing one synchronous generator in area resulting in deteriorated damping performance of the local area 1 and inter-area mode. This can be happened due to the different dynamic characteristic between large-scale WPP and traditional synchronous generator. It is observed that the eigenvalue of local mode area 2 remains its position. It is suggested that the proximity of WPP is also play important role in the system dynamic.

Adding SMES in large-scale WPP as additional devices resulting on eigenvalue of local mode area 1 and inter-area mode move toward left half plane. It is found that by installing SMES in large-scale WPP the damping performance of the system is enhanced. It is also found that the best damping performance is provided by system with SMES optimized by FA indicated by higher value of damping and more negative value of eigenvalue.

\subsection{Non-linear time domain simulation}

To verify the modal (eigenvalue and damping ration) analysis, time domain simulation is then conducted. To investigate the dynamic response of the system, a small perturbation is made by giving 0.05 step input of load changing. Fig. 4 shows the oscillatory condition of generator 1 . It is observed that a modified system has a lower rotor speed oscillation than the base case systems. Table 3 illustrates the detailed overshoot and settling time comparison of different scenario. It is noticeable that, by adding SMES as additional devices in large-scale WPP, the rotor speed oscillation of generator 1 is decreased. It is also found that the best oscillatory condition is provided by system with SMES based on FA indicated by smallest overshoot and fastest

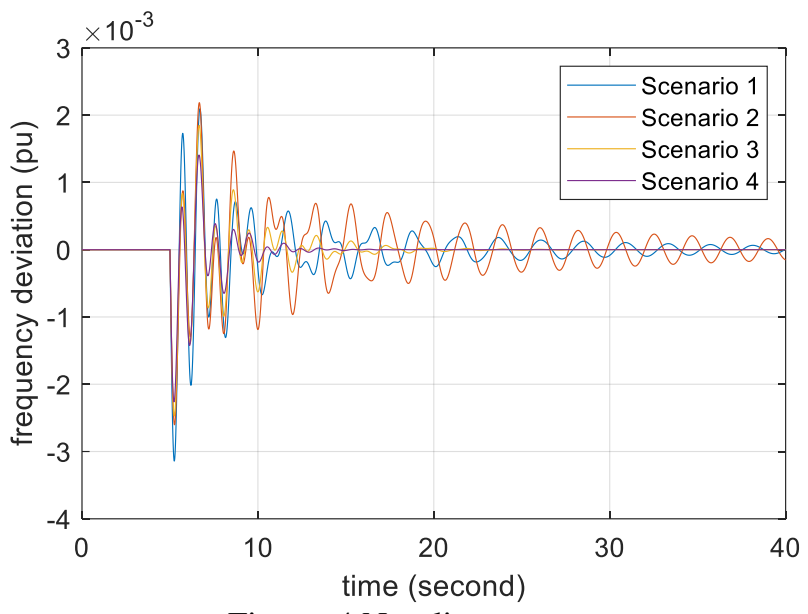

Figure. 4 Non-linear response

Table 3. Detailed features of Fig. 4

\begin{tabular}{|c|c|c|c|c|}
\hline Index & $\begin{array}{c}\text { Scenari } \\
\text { o 1 }\end{array}$ & $\begin{array}{c}\text { Scenari } \\
\text { o 2 }\end{array}$ & $\begin{array}{c}\text { Scenari } \\
\text { o 3 }\end{array}$ & $\begin{array}{c}\text { Scenari } \\
\text { o 4 }\end{array}$ \\
\hline $\begin{array}{c}\text { Oversho } \\
\text { ot }\end{array}$ & - & - & - & - \\
0.00314 & 0.00260 & 0.00247 & 0.00226 \\
& 2 & 3 & 2 & 1 \\
\hline $\begin{array}{c}\text { Settling } \\
\text { time }\end{array}$ & $>35$ & $>35$ & 20 & 10 \\
\hline
\end{tabular}

Table 4. TKE value under different scenarios

\begin{tabular}{|c|c|c|c|c|}
\hline Index & $\begin{array}{c}\text { Scenario } \\
\text { 1 }\end{array}$ & $\begin{array}{c}\text { Scenario } \\
\mathbf{2}\end{array}$ & $\begin{array}{c}\text { Scenario } \\
\mathbf{3}\end{array}$ & $\begin{array}{c}\text { Scenario } \\
\mathbf{4}\end{array}$ \\
\hline TKE & 0.000032 & 0.000022 & 0.000019 & 0.000017 \\
\hline
\end{tabular}

settling time as shown in table 3. Moreover, the increased damping observed in eigenvalue and damping ratio analysis is verified by the time domain result.

\subsection{Transient kinetic energy assessment}

In this case study, the focus is on investigating the transient kinetic energy (TKE) on the power plant [27]. The TKE assessment is used to investigated how much mechanical energy have been used by some system in the transient condition. In this study the smaller the value the less the mechanical energy has been used. The mathematical calculation of TKE can be described using (15).

$$
T K E=\sum_{i=1}^{n} \frac{1}{2} J_{i} \cdot \Delta \omega_{i}^{2}
$$

In (15), the angular momentum of the rotor at synchronous speed and speed deviation of $i^{\text {th }}$ generator in a system with $n$ machines are described as $J_{i}$ and $\Delta \omega_{i}$. Table 4 shows the TKE value comparison of G1 under different scenarios. It is noticeable that the TKE value for G1 is the smallest one when proposed controller method is added to the system. 


\section{Conclusions}

This paper focused on designing SMES parameter using FPA for ancillary services on WPP. From simulation results it is found that adding SMES as additional controller of WPP could enhance the dynamic performance of the system. The best performance is provided by the proposed method. This is indicated by the highest damping value for local mode 1 and inter-area mode $(0.087$ for local mode 1 and 0.202 for inter-area mode) compared to the other scenarios. In addition, the proposed method could also reduce the kinetic energy of the system (TKE=0.000017). Further research can be utilized by identified the best location of SMES. Developing additional controller such as virtual inertia controller can also be considered for the further research.

\section{Conflicts of interest}

"The authors declare no conflict of interest."

\section{Author contributions}

"Conceptualization, Herlambang Setiadi, Dimas Anton Asfani, Tigor Hamonangan Nasution; methodology, Herlambang Setiadi; Herlambang Setiadi, Awan Uji Krismanto and Muhammad Abdillah; validation, Herlambang Setiadi, Dimas Anton Asfani, Tigor Hamonangan Nasution; format analysis, Awan Uji Krismanto, Muhammad Abdillah and Herlambang Setiadi; investigation, Herlambang Setiadi, Dimas Anton Asfani, Tigor Hamonangan Nasution,; resources, Herlambang Setiadi; writing original draft preparation, Herlambang Setiadi; writing review and editing Herlambang Setiadi, Awan Uji Krismanto, Muhammad Abdillah; visualization, Herlambang Setiadi, Dimas Anton Asfani. All authors have read and agreed to the published version of the manuscript".

\section{Appendix}

Table 5. List of notations used in this paper

\begin{tabular}{|l|l|}
\hline Symbol & Meaning \\
\hline$T_{d c}$ & Time delay of the converter \\
\hline$I_{d}$ & Current in the inductor \\
\hline$E_{d}$ & $\begin{array}{l}\text { DC voltage applied in } \\
\text { inductor }\end{array}$ \\
\hline$k_{0}$ & Gain constant \\
\hline$L$ & Inductor coil \\
\hline$k_{i d}$ & Feedback gain \\
\hline$\omega_{g}$ & $\begin{array}{l}\text { Mechanical angular speed } \\
\text { of generator }\end{array}$ \\
\hline$B_{m}$ & Damping coefficient \\
\hline$\tau_{w_{g} g}$ & Aerodynamic torque \\
\hline$\tau_{e}$ & Electromechanical torque \\
\hline
\end{tabular}

\begin{tabular}{|l|l|}
\hline$J_{e q}$ & Equivalent inertia \\
\hline$g$ & Parameter of generator side \\
\hline$R_{s}$ & Stator resistance \\
\hline$L_{i d}, L_{i q}$ & Leakage inductances \\
\hline$L_{d}, L_{q}$ & Generator inductances \\
\hline$\omega_{e}$ & Electrical rotating speed \\
\hline$\psi_{f}$ & Magnetic flux \\
\hline$p$ & Poles \\
\hline
\end{tabular}

\section{Acknowledgment}

The Authors is very grateful to Universitas Airlangga, Institut Teknologi Sepuluh Nopember and Universitas Sumatra Utara for funding this research through Program Penelitian Kolaborasi Indonesia (PPKI) grant (grant number:170/UN3.15/PT/2021).

\section{References}

[1] A. U. Krismanto, N. Mithulananthan, H. Setiadi, E. Y. Setyawan, and M. Abdillah, "Impacts of grid-tied microgrid on stability and interaction of power systems considering RE uncertainties", Sustain. Energy, Grids Networks, Vol. 28, p. 100537, 2021, doi: https://doi.org/10.1016/j.segan.2021.100537.

[2] A. U. Krismanto, I. Soegiarto, A. Lomi, I. B. Sulistiawati, H. Setiadi,and M. Abdillah, "Probabilistic Voltage Profiles Analysis of Power System with Large Scale Wind Power Integration", International Journal of Intelligent Engineering and Systems, Vol. 14, No. 5, pp. 269-282, 2021.

[3] A. U. Krismanto, N. Mithulananthan, A. Lomi, H. Setiadi, and M. Abdillah, "Copula-Monte Carlo Based Probabilistic Oscillatory Stability Analysis of Microgrid", International Journal of Intelligent Engineering and Systems, Vol. 14, No. 5, pp. 479-491, 2021.

[4] S. Dhundhara and Y. P. Verma, "Capacitive energy storage with optimized controller for frequency regulation in realistic multisource deregulated power system", Energy, Vol. 147, pp. 1108-1128, 2018, doi: https://doi.org/10.1016/j.energy.2018.01.076.

[5] Y. Arya, "AGC performance enrichment of multi-source hydrothermal gas power systems using new optimized FOFPID controller and redox flow batteries", Energy, Vol. 127, pp. 704-715, 2017, doi: https://doi.org/10.1016/j.energy.2017.03.129.

[6] M. Khasanov, S. Kamel, C. Rahmann, H. M. Hasanien, and A. A. Durra, "Optimal distributed generation and battery energy storage units integration in distribution systems considering power generation uncertainty", IET Gener. 
Transm. Distrib., Vol. 15, No. 24, pp. 3400-3422, 2021.

[7] M. G. Molina and P. E. Mercado, "Power Flow Stabilization and Control of Microgrid with Wind Generation by Superconducting Magnetic Energy Storage", IEEE Transactions on Power Electronics, Vol. 26, No. 3. pp. 910-922, 2011, doi: 10.1109/TPEL.2010.2097609.

[8] M. Ramírez, R. Castellanos, G. Calderón, and O. Malik, "Placement and sizing of battery energy storage for primary frequency control in an isolated section of the Mexican power system", Electr. Power Syst. Res., Vol. 160, pp. 142-150, 2018, doi: https://doi.org/10.1016/j.epsr.2018.02.013.

[9] J. Hartono, N. Hariyanto, F. S. Rahman, T. Kerdphol, M. Watanabe, and Y. Mitani, "Power System Stabilizer Tuning to Enhance Kalimantan Selatan - Tengah and Kalimantan Timur System Interconnection Stability Using Particle Swarm Optimization", In: Proc. of 2018 5th International Conference on Electric Power and Energy Conversion Systems (EPECS), 2018, pp. 1-6, doi: 10.1109/EPECS.2018.8443361.

[10] R. Shang, L. Jiao, F. Liu, and W. Ma, "A Novel Immune Clonal Algorithm for MO Problems", IEEE Trans. Evol. Comput., Vol. 16, No. 1, pp. 35-50, 2012, doi: 10.1109/TEVC.2010.2046328.

[11] S. Wang, L. Yu, L. Wu, Y. Dong, and H. Wang, "An Improved Differential Evolution Algorithm for Optimal Location of Battery Swapping Stations Considering Multi-Type Electric Vehicle Scale Evolution", IEEE Access, Vol. 7, pp. 73020-73035, 2019, doi: 10.1109/ACCESS.2019.2919507.

[12] S. Paszek and A. Nocoń, "Parameter polyoptimization of PSS2A power system stabilizers operating in a multi-machine power system including the uncertainty of model parameters", Appl. Math. Comput., Vol. 267, pp. 750-757, 2015, doi: https://doi.org/10.1016/j.amc.2014.12.013.

[13] T. Kerdphol, K. Fuji, Y. Mitani, M. Watanabe, and Y. Qudaih, "Optimization of a battery energy storage system using particle swarm optimization for stand-alone microgrids", Int. J. Electr. Power Energy Syst., Vol. 81, pp. 32-39, 2016, doi: https://doi.org/10.1016/j.ijepes.2016.02.006.

[14] H. Setiadi, N. Mithulananthan, and R. Shah, "Design of wide-area POD with resiliency using modified DEA for power systems with high penetration of renewable energy", IET Renew. Power Gener., Vol. 13, No. 2, pp. 342-351, 2018.
[15] M. Singh, R. N. Patel, and D. D. Neema, "Robust tuning of excitation controller for stability enhancement using multi-objective metaheuristic Firefly algorithm", Swarm Evol. Comput., Vol. 44, pp. 136-147, 2019, doi: https://doi.org/10.1016/j.swevo.2018.01.010.

[16] D. Chitara, K. R. Niazi, A. Swarnkar, and N. Gupta, "Cuckoo Search Optimization Algorithm for Designing of a Multimachine Power System Stabilizer", IEEE Trans. Ind. Appl., Vol. 54, No. 4, pp. 3056-3065, 2018, doi: 10.1109/TIA.2018.2811725.

[17] K. Jagatheesan, B. Anand, and S. Samanta, "Flower Pollination Algorithm Tuned PID Controller for Multi-source Interconnected Multi-area Power System”, Appl. Flower Pollinat. Algorithm its Var., p. 221, 2021.

[18] A. U. Krismanto, N. Mithulananthan, and O. Krause, "Stability of Renewable Energy based Microgrid in Autonomous Operation", Sustain. Energy, Grids Networks, Vol. 13, pp. 134-147, 2018, doi: https://doi.org/10.1016/j.segan.2017.12.009.

[19] M. Yin, G. Li, M. Zhou, and C. Zhao, "Modeling of the Wind Turbine with a Permanent Magnet Synchronous Generator for Integration", in 2007 IEEE Power Engineering Society General Meeting, 2007, pp. 1-6.

[20] A. Rolan, A. Luna, G. Vazquez, D. Aguilar, and G. Azevedo, "Modeling of a variable speed wind turbine with a Permanent Magnet Synchronous Generator", in 2009 IEEE International Symposium on Industrial Electronics, 2009, pp. 734-739.

[21] Y. Zou and J. He, "Comprehensive modeling, simulation and experimental validation of Permanent Magnet Synchronous generator wind power system", In: Proc. of 2016 IEEE/IAS 52nd Industrial and Commercial Power Systems Technical Conference (I\&CPS), 2016, pp. 1-9.

[22] A. Pappachen and A. P. Fathima, "Load frequency control in deregulated power system integrated with SMES-TCPS combination using ANFIS controller", Int. J. Electr. Power Energy Syst., Vol. 82, pp. 519-534, 2016, doi: https://doi.org/10.1016/j.ijepes.2016.04.032.

[23] R. Peesapati, V. K. Yadav, and N. Kumar, "Flower pollination algorithm based multiobjective congestion management considering optimal capacities of distributed generations", Energy, Vol. 147, pp. 980-994, 2018, doi: https://doi.org/10.1016/j.energy.2018.01.077.

[24] H. Setiadi, N. Mithulananthan, R. Shah, K. Y. Lee, and A. U. Krismanto, "Resilient wide-area multi-mode controller design based on Bat 
algorithm for power systems with renewable power generation and battery energy storage systems", IET Gener. Transm. Distrib., Vol. 13, No. 10, pp. 1884-1894, 2019.

[25] H. Setiadi, N. Mithulananthan, R. Shah, T. Raghunathan, and T. Jayabarathi, "Enabling resilient wide-area POD at BESS in Java, Indonesia $500 \mathrm{kV}$ power grid", IET Gener. Transm. Distrib., Vol. 13, No. 16, pp. 37343744, 2019.

[26] H. Setiadi, N. Mithulananthan, A. U. Krismanto, and I. Kamwa, "Optimization based Design of Dual Input PSS for Improving Small Signal Stability of Power System with RESs.", Int. J. Electr. Eng. Informatics, Vol. 11, No. 4, 2019.

[27] A. Sajadi, R. Preece, and J. V Milanovic, "Establishment multidimensional transient stability boundaries for power systems with uncertainties", In: Proc. of 2018 Power Systems Computation Conference (PSCC), 2018, pp. 18. 